\title{
パピーウォーカー経験の有無による 生後1年間の問題行動出現の違いについて
}

\author{
水越 美奈 ${ }^{1)}$ 、中村 有香 ${ }^{1)}$ 、細井 淳子 ${ }^{1)}$ 、及川 友恵 ${ }^{1)}$ 2)、関口 歩 2)、中村 透 ${ }^{2)}$ \\ 1) 日本獣医生命科学大学獣医学部獣医保健看護学科 \\ 2）財団法人日本盲導犬協会神奈川訓練センター
}

\section{Difference of behavior problems of guide dog puppies by puppy walking experience.}

Mina Mizukoshi ${ }^{1)}$ 、Yuka Nakamura ${ }^{1)}$,Junko Hosoi ${ }^{1)}$ 、Tomoe Oikawa ${ }^{1)}{ }^{2)}$ 、Ayumi Sekiguchi ${ }^{2)}$, Toru Nakamura ${ }^{2)}$

1) School of Veterinary Nursing \& Technology, Nippon Veterinary E Life Science University

2) Japan Guide Dog Association, Kanagawa training center

\section{抄 録}

パピーウォーキング中の問題行動の出現について、生後 3 カ月から 12 カ月齢の間で、それ以前のパピー ウォーカー経験の有無で比較を行った。質問は 2005 年 3 月 1 日から 2008 年 7 月 16 日生まれのラブラドー ル・レトリーバーをパピーウォーキングした193家庭に対して、毎月6つの問題行動 (排泄の失敗、甘咬み、 破壊行動、散歩時のリードの引っ張り、人への飛びつき、無駄吠え) の有無を 2 者選択で行った。「排泄の 失敗」と「甘咬み」では 3 力月齢時のみで有意差 $(\mathrm{P}<0.05)$ が、「破壊行動」、「散歩時の引つ張り」、「人へ の飛びつき」では飼育初期から中期で有意差 $(\mathrm{p}<0.05)$ が見られたが、「無䭾吠え」では全期間にわたっ て有意差は認められなかった。またいずれの項目でも 10 力月齢以上では有意差は見られなかった。この ことから過去の飼育経験は特に飼育初期に効果を発揮することがわかった。またいずれの項目に打いて も月齢による出現傾向や推移は $\mathrm{PW}$ 経験者と未経験者で同様であったことから、各項目に対するアドバ イスにはそれぞれ適切な時期があることが示唆された。

キーワード：盲導犬、子犬、問題行動、パピーウォーカー

\section{Abstract}

This study was conducted to gather information on the behavior problems during puppy walking (3 month old to 12 month old), and draw a comparison between novice and experienced puppy walker. The questionnaire was answered in the presence or absence about 6 problems (housebreaking, playbiting, destructiveness, pull on leash, jump on people, and excessive barking) each months of age. A question survey was taken 193 puppy walkers who brought up Labrador Retrievers that were born from March $1^{\text {st }} 2005$ to July $16^{\text {th }}$ 2008. Prevalence of "housebreaking" and "play-baiting" were shown significant differences $(\mathrm{p}<0.05)$ on only 3 months of age. And prevalence of "destructiveness", "pulling on leash" and "jumping on people" were shown significant difference $(p<0.05)$ from early to medium period of puppy walking. In "excessive barking”, significant difference was not found in all months. It was shown that experienced puppy walkers made good use of their experience in early and medium period of puppy walking. And because the movements of appearance ratio in all behaviors were kept parallel to another ones in all months, it was suggested that there was the time of advice that was appropriate for each behavioral problems.

Keywords : Guide dogs for the blind, Puppy, Behavior problem, Puppy walker 


\section{I . はじめに}

盲導犬はその育成施設に打いて身体的、行動的を含め た計画的な繁殖と選択、そして盲導犬としての歩行訓練 を経て育成される。またほとんどの盲導犬育成施設では、 育成過程に打ける子犬期の 2 力月齢から約 1 年間を子犬 飼育ボランティア (パピーウォーカー、以下 $\mathrm{PW}$ ) の家庭 で育てるパピーウォーキングシステムを持つ。つまりほ とんどの盲導犬の子犬は最初の 1 年間を $\mathrm{PW}$ と一般的に 呼ばれるボランティア家庭で育てられる。

盲導犬育成に打けるパピーウォーキングシステムは、 子犬を一般家庭の中で育てることで様々な人や環境に対 して社会性を身につけるとともに、人間社会の中での適 切な行動やトイレのしつけなどの基礎的なトレーニング を子犬に学ばせることを目的としている。一般家庭に預 けるもう一つの理由としては、飼い主 (人) を信頼し、紏 を作る経験をすることが挙げられる。盲導犬とその使用 者は相互に信頼関係を持つことで、協調した満足な歩行 を得ることができると言われている1)。またVoithらは 犬の問題行動の発現はトレーニングがうまくいかないた めよりむしろ、犬と飼い主の関係がうまくいっていない ことが原因になっていると報告して打り ${ }^{2)}$ 、幼少期から 人との信頼関係を築くことは犬の将来にとって重要であ ることは明らかである。

パピーウォーキングはボランティアに支えられている 活動であるため、何度も繰り返し行う家庭もあるが、家 庭の事情等により 1 頭限りで $\mathrm{PW}$ を辞めてしまう家庭も あり、PWの構成は常に流動的である。また初めて $\mathrm{PW}$ を行う家庭では犬を飼うこと自体が初めてである場合が ほとんどである。このように $\mathrm{PW}$ の犬の飼育やしつけの 経験はさまざまであると考えられる。

犬を初めて飼う飼い主はその子犬に対する期待度は大 きく、そのイメージは成犬であり、そして見た目である ことがほとんど ${ }^{3)}$ と言われている。また犬を放棄してし まった飼い主の多くは基本的な犬についての知識が久け ていたことが原因であったことが報告されている4)。こ れらを考慮すると、盲導犬候補の子犬を育てた経験があ る $\mathrm{PW}$ 経験者とそうでない $\mathrm{PW}$ 初心者での間でも盲導犬 候補の子犬に対するイメージや期待度、心構えはかなり 異なるのではないかと考えられる。またこれらの考えの 違いは、両者間に打ける子犬を飼育する上での行動上の 問題に対する意識にも影響するのではないだろうか。

また犬の性質は犬種によって傾向があることがいくつ か示されている5，6，7),8)。そのため、同じ犬種を育てた
経験は次に同じ犬種の子犬を育てるのに役立つことは容 易に想像できる。しかし、それぞれ個々の性質は犬種的 側面の違いによるものだけではない。いくつかの性質(遊 び好き、好奇心、不安、社会性）は同犬種でも個体により

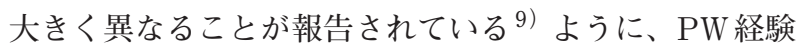
者でも前回の子犬飼育で経験したこととは異なる悩みが 生じることも考えられる。

家庭犬に打いては、行動上の問題は1歳齢以下であっ ても犬の放棄や安楽死の主要な原因のひとつであり 10), 11）,12）,13)、また犬のしぐさや行動は、飼い主のその犬に 対する親しみや愛着に重要な役割を演じている ${ }^{14) 。 つ ~}$ まり犬の飼育初期の行動上の問題の有無は、家庭犬がそ の家庭で幸せに暮らしていくためにも大きな影響を与え ると考えられる。これらの点では盲導犬に限らず、飼育 初心者に対して飼育初期に適切な指導を与えることはと ても重要なことである。

前回、我々は PW 経験の有無が子犬 ( 3 力月齢) の飼育 に影響を与えるか否かについて調査を行った。そこで 我々はPW 経験者と未経験者の間で「排泄の失敗」「飛 びつき」、「破壊行動」、「甘咬み」について出現率に有意 差があったことから、PW未経験者に対してこれらの行 動についての指導を飼育前に行うことは特に大切である ことを示した ${ }^{15)}$ 。

今回、我々は調查期間を広げ、行動上の問題を継続的 に調査することで月齢によってその相違に変化があるの か、過去の子犬飼育経験がどれだけ次の飼育に役立てる ことができるのかについて調査し、さらに $\mathrm{PW}$ や飼い主 に対して「いつ、どのような」アドバイスを与えれば、そ のアドバイスが効果的に機能することができるかについ て検討を行なったので報告する。

\section{II. 方法}

財団法人日本盲導犬協会神奈川訓練センターが、飼育 指導を目的としてPWに対して行っていた月齢報告書の 中で 2005 年 3 月 1 日から 2008 年 7 月 16 日までの期間に 生まれたラブラドール・レトリーバー 193 頭の 3 カ月齢 時から 12 力月齢時データを使用した。その中から、「排 泄の失敗」「甘咬み」「破壊行動」「散歩時の引っ張り」、 「人の飛びつき」、「無駄吠え」の発現の有無の数を抽 出した。以上の質問に対してイエスあるいはノーの答え があるもののみを有効データとし、無回答だったものは データから除き、その有効データを $\mathrm{PW}$ の経験の有無で 分類した。実際に使用したデータは表 1 の打りであっ た。そしてPW経験者と未経験者に扔いて各対象行動出 
表1 実際に使用したデータ

\begin{tabular}{|c|c|c|}
\hline 月齢 & 飼育経験あり & 飼育経験なし \\
\hline 3 か月 & 71 (o`33: 우 38) & 101 (ふ752：우49） \\
\hline 4 か月 & 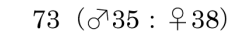 & 97（○フ51：우46) \\
\hline 5 か月 & 65 (o'28: 우 37$)$ & $93\left(\right.$ o $^{\top} 46:$ 우47) \\
\hline 6 か月 & 67 ( (ㄱ30: 우 37) & 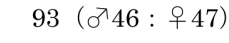 \\
\hline 7 か月 & 63 (o27: 우 37) & 91（oフ43: 우48) \\
\hline 8 分月 & 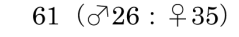 & 86 ( ( \\
\hline 9 か月 & 59 (o’25 : 우 34) & 81 (ơ 40: 우41) \\
\hline 10 か月 & 48（o21: 우27） & 75 (o 40 : 우 35$)$ \\
\hline 11 か月 & 42 (o19: 우 23$)$ & 69 (ㅇㄱ 36 : 우33) \\
\hline 12 か月 & 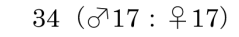 & 47 (○`21: 우26) \\
\hline
\end{tabular}

現率を 1 力月ごとに比較し、母比率の差の検定、カイ二 乗検定を行った。

\section{III. 結果}

\section{1. 排泄の失敗}

3 力月齢時でのみ、 $\mathrm{PW}$ 未経験者での出現率が明らかに 高い $(\mathrm{P}<0.05)$ ことが示された。しかし 4 力月齢以降で は出現率の明らかな違いは認められず、月齢による減少

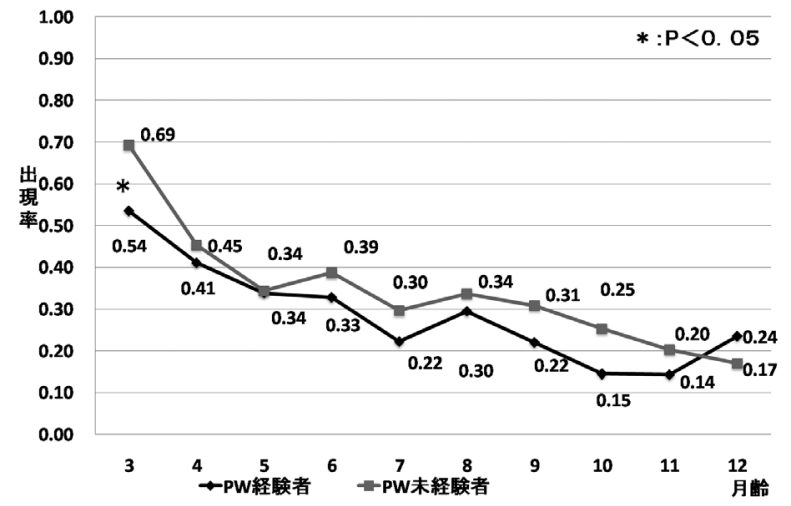

図1排泄の失敗

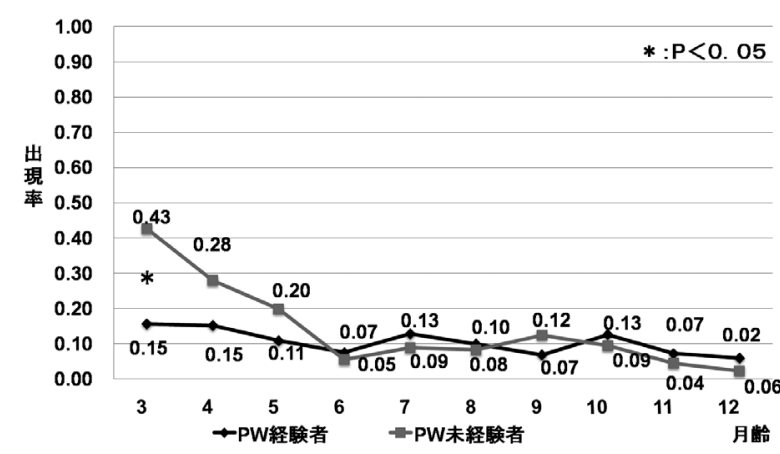

図2 甘咬み
傾向は両者に扔いてほとんど同様であった(図1)。

\section{2. 甘咬み}

3 力月齢で $\mathrm{PW}$ 未経験者での出現率は明らかに高く ( $<<0.05) 、 そ の$ 差は約 3 倍程度あった。しかし有意差は、 「排泄の失敗」と同様に 3 力月齢のみでみられた。6力月 齢以降での出現率は、両者でほとんど変わりはなかった (図2)。

\section{3. 破壊行動}

3、4、6、8 月月齢で $\mathrm{PW}$ 未経験者の出現率は明らかに高 かった $(\mathrm{p}<0.05)$ が、9 カ月齢以降の出現率ではほとんど 変わりはなかった。また両者ともに同じような減少経過 を示した(図3)。

\section{4. 散歩時のリードの引っ張り}

両者とも 4 力月齢で出現率は急激に上昇し、 $\mathrm{PW}$ 未経験 者の出現率は $6 、 9$ 力月齢を除き、 4 力月齢から 10 力月齢 まで明らかに高かった（p<0.05）。また全ての期間にお いて PW 経験者と未経験者の出現率はほぼ平行に推移し た(図4)。

\section{5. 人への飛びつき}

5、6、7 カ月齢と 9 力月齢で $\mathrm{PW}$ 未経験者の出現率は明 らかに高かった（p<0.05）。また全ての期間において出 現率はほぼ平行に推移したが、10 カ月齢以降では両者の 出現率にほとんど変わりはなかった(図5)。

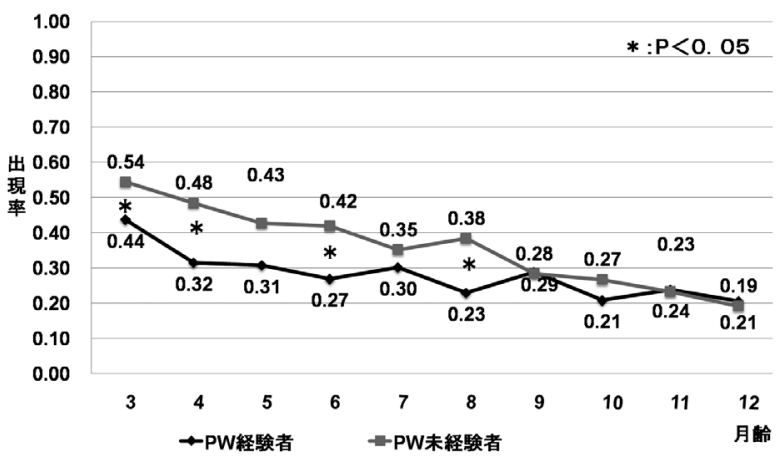

図3 破壊行動

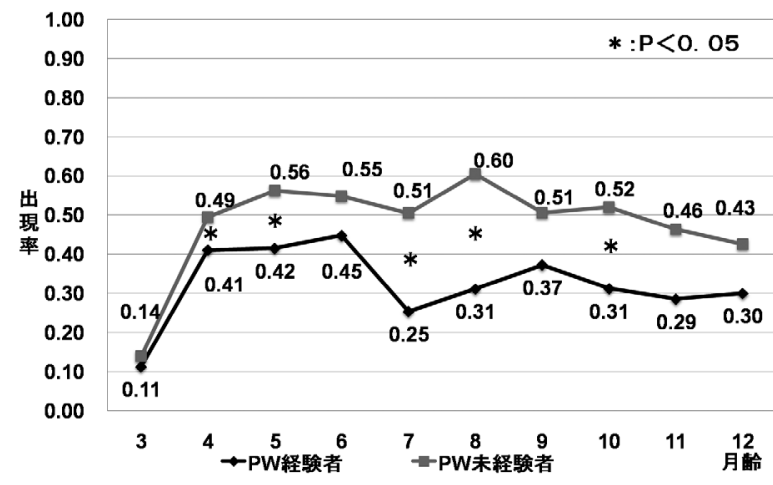

図4 散歩中のリードを引っ張り 


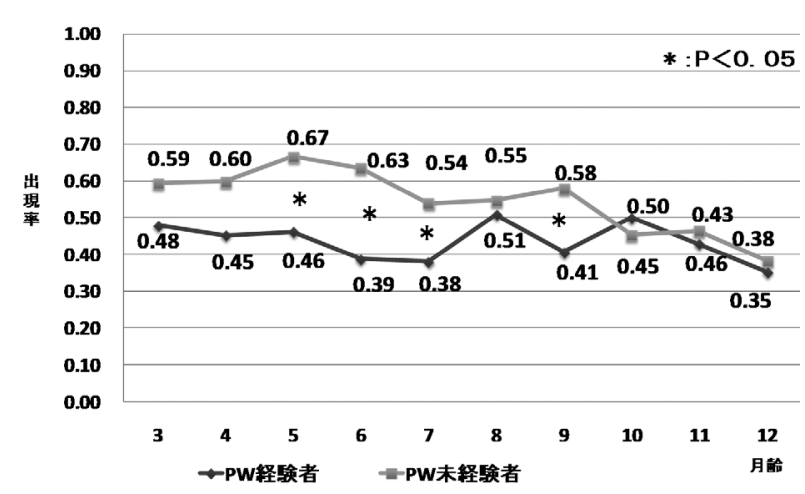

図5人への飛びつき

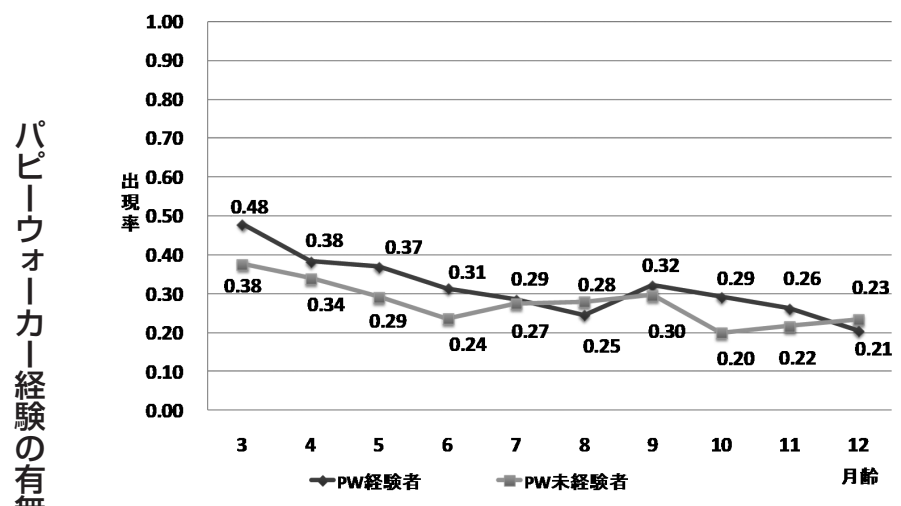

図6 無駄吠え

\section{6. 無䭾吠え}

全ての月齢で出現率に差はみられなかった。出現率は 両者とも月齢に伴って減少傾向がみられたが、その推移 は両者でほとんどかわらなかった。有意差は見られなか ったが、ほとんどの月齢で $\mathrm{PW}$ 経験者のほうがわずかに 未経験者より出現率が高かった(図6)。

\section{N. 考察}

「排泄の失敗」と「甘咬み」の出現率は PW 経験者と未 経験者に打いて特に飼育初期に大きな差異があることが 示された。つまり PWの経験は子犬の飼育初期に打いて、 「排泄の失敗」と「甘咬み」に対して特に役立っているこ とから、これらの問題の予防や対処法は、過去の飼育経 験によって以前の子犬から学び取った技術が他の子犬に も応用することができると考えられた。「排泄の失敗」や 「甘咬み」は子犬の飼育初期に最もよく見られ、かつ最も 飼い主が困る問題のひとつである。新規 $\mathrm{PW}$ や犬を始め て飼う人に対して子犬を家に迎え入れる前にこれらの適 切な指導を行えば、飼育未経験者での出現率を抑えるこ とにつながるのではないだろうか。

「破壊行動」や「散歩中のリードの引っ張り」、「人に対 する飛びつき」では、過去の飼育経験がパピーウォーキ
ングの早期から中期で役立つことが示された。これらの 問題は、特に若年期でトラブルになることが多い。抏そ らく $\mathrm{PW}$ 経験者では、若年期で強く現れるであろう行動 を予測することができたことから、早めの対応をするこ とでこれらの行動の発現率を抑えることができたのでは ないだろうか。これらのうち、「破壊行動」と「人に対す る飛びつき」はパピーウォーキングの中後期 (9、10 カ月 齢以降）から、両者の出現率にはあまり相違が見られな くなった。しかし「散歩中のリードのひっぱり」では全 体にわたってその相違には変化がなく、PW未経験者で は一貫して出現率が高いことが示された。「散歩中のリ 一ドの引っ張り」行動はその他の行動より学習要素が強 い行動であることから、経験でより強化されることが考 えられ、早期からの対応がその後の行動に大きな影響を 与えるのではないかと考えられた。

「無駄吠え」では、PW 経験者と未経験者において全期 間で有意な相違は見られなかった。つまり「無駄吠え」 に対しては、過去に打ける犬の飼育経験はほとんど役に 立たないと考えられた。吠え行動には様々な原因が存在 する。さらに刺激に対する反応も個体によって幅がある ため、過去の経験で培った対応が効果を示さなかったの かもしれない。

また今回の結果から、ほとんどの項目でそれぞれの月 齢では PW 経験者と未経験者間で出現率の差異はあって も、月齢によるグラフの推移は同様な動き方を示してい た。推移の動向が似ているということは、各々の問題に は起こりやすい時期というものが存在し、それは飼い主 の飼育経験には関係なく起こるということが考えられ る。つまりそれぞれの問題行動にはアドバイスに適する 時期がそれぞれに存在すると考えられるのではないだろ うか。

つまり初めて犬を飼う飼い主や PW に対しては「排泄 のしつけ」と「甘咬みの抑制」、「飼い主の大事なものを 壊さないようにする」については子犬が新しい家に迎え 入れられる前に、「リードを引っ張らずに歩く」と「人に 対して飛びつかずに挨拶する」については飼育初期に指 導を行うようにすれば、より快適に楽しく子犬を飼育す ることができるだろう。「散歩のときにリードを引っ張 って歩く」は有意差こそなかったが、PW 経験者と未経 験者で 12 力月齢においても唯一出現率に差が見られた。 「リードを引っ張って歩く」犬は、盲導犬の訓練に入っ た場合、それを矯正するのに余計な時間をその教育に費 やさなければいけないと考えられる。このことから、パ ピーウォーキングの中期から後期にかけて、リードを引 つ張らずに歩くことについてしっかりと指導を行うこと 
は、PWに対して役立つだけでなく、その後の盲導犬訓練 の時間短縮にも貢献するかもしれない。また吠える問題 に関しては、飼育経験の有無に関わらず問題を引き起こ す割合は変わらないので、飼育経験に関わらず早期から の適切な指導が大切ではないかと考えられた。

今回の調査は子犬の問題行動をパピーウォーキングの 経験の有無で比較を行ったが、これらの結果は家庭犬の 子犬の指導にも応用することができると考えられる。過 去の報告によると、基本トレーニングクラスに通わなか った犬はより放棄される危険性が 68.1 \% 増し ${ }^{16)}$ 、子犬 の社会化クラスに通った犬は放棄される可能性が低くな る10) ことが示されている。今回の結果からも早期に何 らかの適切な対応があれば、問題行動の出現率は抑えら れる可能性が示唆されることから、飼い主や犬に対する 早期の教育はとても重要であることが考えられた。

\section{V. 結論}

今回の結果から、PW 経験者と未経験者の間で子犬の 多くの問題行動の出現率に相違が見られ、その相違は特 に飼育初期から中期に発揮されることがわかった。しか し飼育後期ではその違いはほとんど見られなかった。つ まり過去の飼育経験は子犬が小さい時に発揮されるが、 時間の経過とともにその過去の経験は現在の経験に相殺 されてしまうのかもしれない。しかし、飼育経験のない 飼い主や PWに対して、飼育開始前や飼育初期に適切な 指導を与えることは、問題行動の出現率を軽減し、飼育 に対するモチベーションを高めると考えられる。

また各々の問題行動の出現率は $\mathrm{PW}$ 経験者と未経験者 間で出現率の差異はあっても、月齢による出現率の推移 は飼育経験に関係なく同様な動きを示した。つまり各々 の問題には起こりやすい時期というものが存在し、各々 の行動に対して適切なアドバイス時期があることが示唆 された。

\section{謝辞}

本研究の実施にあたり、(財) 日本盲導犬協会神奈川 訓練センターの職員の皆さまと子犬飼育ボランティアの 方々のご協力をいただきましたことに深く感謝致します。

\section{文献}

1) SANDERS, C. (2000) . The impact of guide dogs on the identity of people with visual impairments. Anthrozoos, 13, 131-139.

2) VOITH, V. L., WRIGHT, J. C., DANNEMAN, P. J. (1992) . Is there a relationship between canine behavior problems and spoiling activities, anthropomorphism, and obedience training?
Appl. Anim. Behav. Sci., 34 (3) , 263-272.

3) MARDER, A. \& DUXBURY, M.M. (2008). Obtain a pet: realistic expectations. Vet. Clin. North. Am. Small. Anim. Pract., 38(5), 1145-62.

4) NEW, J. C., SALMAN, M.D., KING, M., et al. (2000). Characteristics of shelter-relinquished animals and their owners compared with animals and their owners in U.S. pet-owning households. J. Appl. Anim. Welf. Sci., 3, 179-201.

5) HART, B. L. \& HART, L. A. (1985). Selecting pet dogs on the basis of cluster analysis of breed behavior profiles and gender. $J$. Am. Vet. Med. Assoc., 186 (11) , 1181-5.

6) HART, B. L. \& MILLER, M. F. (1985) . Behavioral profiles of dog breeds: a quantitative approach. J. Am. Vet. Med. Assoc., 186 (11) , 1175-80.

7) BRADSHAW, J. W. S., GOODWIN, D., LEA, A.M., et al. (1996) . A survey of the behavioral characteristics of purebred dogs in the United Kingdom. Vet. Rec., 138 (19), 465468.

8) TAKEUCHI,Y. \& MORI,Y. (2006) . A comparison of the behavioral profiles of purebred dogs in Japan to profiles of those in the United States and the United Kingdom. J. Vet. Med. Sci., 68(8), 789-796.

9) SVERTBERG, K. (2006) . Breed-typical behavior in dogs - historical remnants or recent constructs? Appl. Anim. Behav. Sci., 96, 293-313.

10) PATRONEK, G. J., GLICKMAN, L. T., BECK, A. M., et al. (1996) . Risk factors for relinquishment of dogs to an animal shelter. J. Am. Vet. Med. Assoc., 209 (3) , 572-81.

11) SCARLETT, J. M., SALMAN, M. D., NEW, J. G. Jr., et al. (1999) . Reason for relinquishment of companion animals in U.S. animal shelters: selected health and personal issues. J. Appl. Anim. Welf. Sci., 2(1) , 41-57.

12) SHORE, E. R. (2005) . Returning a recently adopted companion animal: adopters' reasons for and reactions to the failed adoption experience. J. Appl. Anim. Welf. Sci., 8(3) , 187-98.

13) HARRON, M. E., LORD, L. K., HILL, L. N., et al. (2007) . Effects of pre-adoption counseling for owners on house-training success among dogs acquired from shelter. J. Am. Vet. Med. Assoc., 231 (4) , 558-62.

14) SERPELL, J. A. (1996) . Evidence for an association between pet behavior and owner attachment levels. Appl. Anim. Behav. Sci., 47, 49-60.

15）水越美奈、及川友恵、北口めぐみ·他 (2009) 。 パピーウォー カー指導に関する一検討 : 子犬飼育経験による行動上の問 題の違いについて. 日本補助犬科学研究, 3(1), 17-22.

16) DUXBURY, M., JACKSON, J., LINE, S., et al. (2003) . Evaluation of association between retention in the home and attendance at puppy socialization classes. J. Am. Vet. Med. Assoc., 223(1), 61-66. 